\title{
An Overview of Alopecias
}

\author{
Ji Qi and Luis A. Garza \\ Department of Dermatology, Johns Hopkins University School of Medicine, Baltimore, Maryland 21287 \\ Correspondence: LAG@jhmi.edu
}

Hair loss is a topic of enormous public interest and understanding the pathophysiology and treatment of various alopecias will likely make a large impact on patients' lives. The investigation of alopecias also provides important insight in the basic sciences; for instance, the abundance of stem cell populations and regenerative cycles that characterize a hair follicle render it an excellent model for the study of stem cell biology. This review seeks to provide a concise summary of the major alopecias with regard to presentation and management, and correlate these to recent advances in relevant research on pathogenesis.

\section{ALOPECIAS: AN INTRODUCTION}

Shakespeare wrote, "There's many a man Shas more hair than wit" in the Comedy of Errors. However, in today's contemporary society, some patients are so troubled by hair loss they might trade wit for more hair if given the opportunity. The study of alopecia is desperately encouraged by society given the importance of hair to most people's identity. Therefore, a better understanding of the pathogenesis and potential treatments of alopecia will be a welcome advancement.

The study of alopecias will also broaden our understanding of the basic biology of the hair follicle, likely the most complicated structure within the skin. Replete with multiple stem cell populations and an intrinsic cycle of regeneration, the hair follicle has become an attractive model within the last $20 \mathrm{yr}$ to study questions about stem cell biology. As in all biological systems, the best clues to critical players are instances in which their perturbation yields functional defects. Thus, human alope- cias represent a rich arena for the study of novel control points for hair follicle function. This article will cover the clinical presentations of major alopecias and delve into recent research regarding pathogenesis.

Hair itself has few physical functions. These include defense against the effects of UV radiation, suppression of heat loss, and tactile sensation. The various hair types consist of terminal, intermediate, and vellus hairs. Terminal hairs fit the classic perception of hair and are the hairs of the scalp, axillae, pubic region, beard, eyebrows, and eyelashes. These are long, pigmented, and thick. Vellus hairs, on the other hand, are short and generally lack pigmentation. These cover the body. Intermediate hairs have characteristics that fall in the middle of the spectrum between terminal and vellus hairs. Loss of hair can be irreversible, causing skin to atrophy and follicular openings to vanish. Such cases are categorized as cicatricial (or scarring, permanent) alopecia. Reversible hair loss is noncicatricial (Wolff et al. 2009).

Editors: Anthony E. Oro and Fiona M. Watt

Additional Perspectives on The Skin and Its Diseases available at www.perspectivesinmedicine.org

Copyright (C) 2014 Cold Spring Harbor Laboratory Press; all rights reserved; doi: 10.1101/cshperspect.a013615

Cite this article as Cold Spring Harb Perspect Med 2014;4:a013615 
Humans are usually born with approximately 5 million follicles, and no new follicles are thought to be added after birth. The hair follicle cycle, which begins in utero, is composed of three stages: anagen, telogen, and catagen. Anagen phase is the longest, lasting an average of $3 \mathrm{yr}$ and ranging from 1 to $6 \mathrm{yr}$ depending on body location. It is also the most prevalent phase, with $90 \%-95 \%$ of all hairs existing in anagen phase at any one point in time. Anagen represents the growth period, comprising extensive mitotic activity, such that longer anagen phase means longer hair (e.g., scalp as opposed to eyebrows, eyelashes, or pubic hair). The hair then involutes during catagen phase through apoptosis of the follicular keratinocytes, leaving a club hair. Telogen is the resting period with inactivity of the organ, persisting 2 to 3 mo on the scalp or longer elsewhere. The club hair is shed and a new anagen hair grows in its place to resume the cycle (Wolff et al. 2009; Habif 2010).

Given its properties of regeneration, the hair follicle is a fascinating organ. Learning about associated pathophysiologies can yield a great deal of insight about human physiology and serve as a model of regeneration for a human organ.

\section{NONCICATRICIAL ALOPECIAS}

\section{Androgenetic Alopecia \\ Clinical Presentation and Management}

Androgenetic alopecia (AGA), also known as patterned hair loss, is the most common type of alopecia in both men and women. Although AGA is a physiological condition, the psychological impact of hair loss can be profound. Half of all men are affected by age 50, whereas $40 \%$ of women are affected by age 70 (Norwood 1975, 2001). However, symptoms may present as early as around the time of puberty. The Hamilton classification system describes the predominant course in men: a receding frontal hairline with bitemporal hair loss that merges with vertex thinning. In women, the anterior hairline is preserved and thinning occurs primarily at the crown, as depicted by the Ludwig pattern. In both cases, the condition progresses gradually. For many men, AGA advances to produce com- plete baldness with retention of only the occipital and temporal hair regions. In contrast, total baldness at any area is rare for women. Hair loss occurs because of the conversion of terminal hairs into vellus hairs that eventually atrophy. The process is attributed to the effect of dihydrotestosterone (DHT) on hair follicles of the scalp, causing them to gradually miniaturize. Diagnosis is made based on clinical presentation, clinical history, and family history of AGA. The condition is characterized by a polygenic inheritance pattern (Table 1) (Paus and Cotsarelis 1999; Habif 2010; Otberg and Shapiro 2012).

Currently, two medications have received Food and Drug Administration approval in the treatment of AGA. Minoxidil, commercially known as Rogaine, is a topical vasodilator that prolongs anagen phase and increases the size of smaller hair follicles. Its exact mechanism of action has yet to be worked out, but recent hypotheses involve modulation of prostaglandin levels (Messenger and Rundegren 2004). Finasteride is an oral medication that inhibits $5 \alpha$-reductase type II, thereby preventing the conversion of testosterone to DHT, without a direct effect on androgen receptors. Minoxidil can be used by both men and women, but benefits of finasteride have not been demonstrated in women with AGA. Both medications must be taken indefinitely for benefits to persist. Surgical treatments such as hair transplants are available as well; weaves and wigs also serve as options (Habif 2010; Otberg and Shapiro 2012).

\section{Recent Research on Pathogenesis}

Recent research has increased knowledge regarding AGA pathogenesis and raised possibilities for the development of new treatment. DHT is traditionally implicated in pattern hair loss, with dermal papilla cells (DP cells) hypothesized as the hormone's target that sends signals to follicular epithelial cells. Researchers have shown Wnt inhibitory dickkopf 1 (DKK-1), a gene under DHT control, to be significantly upregulated in DP cells located in balding scalp areas (Kwack et al. 2008). The possible up-regulation of DKK-1 in AGA fits current models, given the importance of Wnt in promoting hair 
An Overview of Alopecias

Table 1. Main features of various alopecias

Noncicatricial alopecias

\section{Androgenetic alopecia}

Most common type of hair loss in both men and women

Onset may be as early as puberty: $50 \%$ of men affected by age $50,40 \%$ of women by age 70

Male pattern: Thinning of the frontal hairline, bitemporal recession, hair loss at the crown

Female pattern: Hair loss at the crown with preservation of the frontal hairline

Caused by the effect of dihydrotestosterone on hair follicles leading to miniaturization

\section{Alopecia areata}

Equally affects both sexes, with usual onset before age 30

Most common areas of hair loss are scalp and beard regions

Round areas of complete hair loss with retained follicular ostia

Exclamation point hairs found at the edges of expanding areas of hair loss are a hallmark sign

Caused by autoimmune destruction of hair follicles involving cell-based and humoral immunity

\section{Telogen effluvium}

Acute telogen effluvium is characterized by diffuse scalp hair loss lasting $<6 \mathrm{mo}$, whereas the duration is $>6 \mathrm{mo}$ for chronic telogen effluvium

Women between ages 30 to 60 are most commonly affected

A stressor event may or may not be present, usually occurring 2-4 mo before onset of hair shedding

$20 \%-50 \%$ of scalp hairs transition prematurely to telogen phase and are shed with normal hair shafts

\section{Anagen effluvium}

Diffuse hair loss characterized by hair breakage during anagen phase

Classic causative agents are radiation therapy and cancer chemotherapy

Affects $80 \%-90 \%$ of scalp hairs with onset within 1-4 wk of exposure

Narrowing, fractured hair shafts constitute a characteristic sign

\section{Loose anagen syndrome}

Typical patient is a blond female aged $2-5$ who presents with diffuse hair loss and short, dull hair

6:1 Female to male ratio among the patient population, which includes adults and dark-haired individuals as well

Greater susceptibility to hair breakage caused by premature keratinization of the inner root sheath, causing impaired adhesion with the hair shaft cuticle

Shorter anagen phase leads to reduced hair length

\section{Trichotillomania}

Patients experience an irresistible urge to pull out their own hair despite negative impacts to their occupational and social function

Childhood trichotillomania affects more boys than girls and resolves spontaneously

Adult trichotillomania affects women much more frequently than men

Often comorbid with mood or anxiety disorders

Short, fractured hairs distributed sparsely and irregularly in affected areas

\section{Traction alopecia}

Results from tension applied to hair for a prolonged period of time, from hairstyles such as tight ponytails and braids, as well as hair-styling devices

Areas under greatest pressure are most affected, usually scalp margins

Especially common among African-American females because of their association with certain hairstyles

Typically hair loss is transient; scarring or inflammation may be observed

Continued 
J. Qi and L.A. Garza

Table 1. Continued

Cicatricial alopecias

\section{Chronic cutaneous lupus erythematosus}

Scaly, erythematous plaques with well-demarcated borders that eventually atrophy, found on sun-exposed areas including scalp

Most common form is discoid lupus erythematosus, accounting for $50 \%-85 \%$ of all cases

Affects more women than men, usually between ages 20-45

Associated with carpet tack sign, describing follicular spikes on the undersurface

Cases among African-Americans are often more severe

\section{Lichen planopilaris}

Considered to be a variant form of lichen planus

Classic lesions are smooth white areas with absent follicle ostia and central scarring; edges are characterized by erythema and scaling around hair follicles

Mostly affects adult women at the crown and parietal areas of the scalp

Due to autoimmune attack on hair follicles mediated by $\mathrm{T}$ lymphocytes

\section{Central centrifugal cicatricial alopecia}

Scarring hair loss that usually begins at the crown and expands outward to affect the entire scalp

Middle-aged African-American females are most commonly affected; individuals of other races rarely present with this condition

May be associated with chemicals and pressure applied to hair

Lymphocyte-rich infiltrates observed at edges of balding lesions with signs of inflammation

development (Watt and Collins 2008). A second pathway that has been found to be elevated in balding scalp involves prostaglandin $\mathrm{D}_{2}$ synthase, as well as its product, prostaglandin $\mathrm{D}_{2}$ $\left(\mathrm{PGD}_{2}\right) . \mathrm{PGD}_{2}$ has been shown in humans and in mice to inhibit hair growth, an effect that requires the expression of $\mathrm{PGD}_{2}$ receptor $\mathrm{G}$ protein-coupled receptor 44 (Garza et al. 2012).

After these early signals, the DP cells found in areas of AGA are known to enter senescence prematurely, and this phenomenon has been linked to the expression of cell cycle regulators $\mathrm{p} 16 \mathrm{INK} 4 \mathrm{a} / \mathrm{pRb}$ (Bahta et al. 2008). After all of these events, an ongoing question has been the status of the hair follicle stem cell compartment in AGA. In a comparison of scalp areas with or without hair loss, investigators demonstrated a relative lack of hair follicle progenitor cells (early stem cell progeny) in balding areas, although numbers of parental stem cells remained unchanged. Impaired transition from stem cell to progenitor cell may contribute to the reduced hair follicle size observed in AGA patients (Garza et al. 2011). This novel research represents potential areas for advancement in therapy.
Also noteworthy are the recent findings in genetic mapping of AGA. Numerous studies have already identified polymorphisms in the $\mathrm{X}$-linked androgen receptor gene that may increase susceptibility for AGA (Zhuo et al. 2012). According to a study conducted on individuals in Sardinia, AGA is also associated with the $\mathrm{X}$-linked gene EDA2R encoding ectodysplasin A2 receptor, independent of linkage disequilibrium (Prodi et al. 2008). An association of AGA with EDA2R would suggest an overlapping defect of hair growth inhibition in ectodermal dysplasia patients with mutations in this pathway (Mikkola and Thesleff 2003). Improved understanding of the genetic basis for AGA will elucidate the underlying molecular mechanisms that give rise to the condition.

\section{Alopecia Areata \\ Clinical Presentation and Management}

Alopecia areata (AA) is a nonscarring form of hair loss that has a lifetime prevalence of approximately $2 \%$. Men and women are equally 
affected, with onset of symptoms occurring most commonly before age 30 . The condition has a hereditary component- $20 \%$ of patients possess at least one first-degree relative with AA. Comorbidities in select patients include autoimmune disorders such as thyroid disease, vitiligo, and atopy. Indeed, hair loss in $\mathrm{AA}$ is understood to occur because of T-lymphocyte-mediated autoimmune attack on hair follicles in anagen phase. Humoral immunity is also involved through hair follicle autoantibodies. The scalp and beard regions are most susceptible, but other areas of the body can be affected as well. Alopecia on the scalp manifests as smooth, round patches of complete hair shaft loss, but with retained follicular openings. At the edges of expanding areas, exclamation point hairs can be found. These are short, fragmented hairs that are thinner at the proximal end and considered a hallmark of AA. Hair loss may progress to alopecia totalis, meaning complete balding at the scalp, or to alopecia universalis, describing loss of all hair on the body. Severe cases are associated with nail pitting (Habif 2010; Gilhar et al. 2012; Otberg and Shapiro 2012).

For $80 \%$ of AA patients, hair regrows spontaneously within a period of $1 \mathrm{yr}$ since onset. Management for the condition is generally focused on modulating the autoimmune response. Corticosteroid injections into affected areas serve as a first-line approach for when hair loss affects $<50 \%$ of the scalp. Topical corticosteroids are widely used and exert greater benefits when used with occlusive dressings. For extensive alopecia, inducing contact dermatitis by applying allergens, a procedure known as topical immunotherapy, provides benefit with some patients and oral corticosteroids represent an additional option. Other measures consist of minoxidil and the experimental use of novel immunosuppressive biologic drugs, although the latter option has yet to show significant benefit in clinical trials (Strober et al. 2005, 2009; Price et al. 2008). Psoralen plus UVA therapy is less commonly used because of inadequate efficacy and associated harms of photoaging and photocarcinogenesis. Nonpharmacological options include hairpieces and temporary tattooing, which helps patients with loss of eye- brow hair (Habif 2010; Gilhar et al. 2012; Otberg and Shapiro 2012).

\section{Recent Research on Pathogenesis}

Perhaps the most important breakthrough in the last several years in the field of AA is a genome-wide association study that uncovered 139 single-nucleotide polymorphisms related to the condition. Implicated genes possessed roles in acquired immunity, including cytotoxic T-lymphocyte-associated antigen 4 (CTLA4), interleukin (IL)-2/IL-21, IL-2 receptor A, and Eos. The human leukocyte antigen region was also involved. Associations with hair follicle genes PRDX5 and STX17 were found as well. Especially interesting was the finding that the cytomegalovirus UL16-binding protein (ULBP) gene cluster yielded a strong correlation, the first time the region has been linked to an autoimmune disorder. ULBPs play a role as ligands for the natural killer (NK) cell receptor NKG2D and thus are part of innate immunity. Further investigation demonstrated that ULBP is overexpressed in affected scalp areas in AA patients (Petukhova et al. 2010). The study has shed fresh insight into the genetics behind AA pathogenesis, which likely involves both innate and adaptive immunity.

There is also evidence that highlights the involvement of NK cells. Hair follicle epithelium in AA patches had markedly elevated numbers of NK cells, whereas few were observed around normal hair follicle epithelium, which expresses significant levels of NK cell inhibitor macrophage migration inhibitory factor (Ito et al. 2008). Another study that explored filaggrin (FLG) gene mutations did not detect a significant relationship between FLG mutations and AA per se. However, the mutations were correlated with higher incidence of atopic dermatitis in AA patients, and among these comorbid patients the prognosis of AA was worse (Betz et al. 2007).

The importance of neuropeptides and the local hormonal axis is an ongoing area of inquiry regarding hair follicle biology and AA. The $\mathrm{C} 3 \mathrm{H} / \mathrm{HeJ}$ mouse AA model has yielded new information in recent years. When AA 
mice were subjected to stress, they showed enhanced hypothalamic-pituitary-adrenal (HPA) axis activity compared with normal mice. The investigators postulate that HPA activity may be modified in the context of AA (Zhang et al. 2009). In the same mouse model, researchers demonstrated that the neuropeptide substance $\mathrm{P}$ might regulate inflammatory response in AA (Siebenhaar et al. 2007). These studies may help unravel additional pathways underlying the disease.

\section{DIFFUSE HAIR LOSS}

\section{Telogen Effluvium}

\section{Clinical Presentation and Management}

Diffuse hair loss, in contrast to AGA and AA, affects the scalp area uniformly. The most common type is telogen effluvium, which is classified as either acute or chronic. Acute telogen effluvium (ATE) involves hair shedding that persists $<6 \mathrm{mo}$. There is usually a trigger that occurs 2-4 mo before onset of hair loss. The cause may be endocrine, in the event of childbirth and hyper/hypothyroidism; nutritional, encompassing crash diets and vitamin A excess; drug-related, most notably anticoagulants and $\beta$-blockers; and stress. Febrile illnesses and malignancies are often implicated as well. The stressor event induces between $20 \%-50 \%$ of scalp hairs to transition to and remain in telogen phase for $\sim 3$ mo until they are shed. Hair shafts remain normal. The process itself is physiological; the abnormality lies in the large number of hairs that are simultaneously affected, as regularly only $5 \%-10 \%$ of hairs are in telogen phase. Patients present suddenly with diffuse hair loss, although complete balding does not occur. Removal of the hair stressor allows for regrowth and recovery of the normal distribution of telogen hairs over several months. In chronic telogen effluvium (CTE), hair loss persists longer than 6 mo. Although ATE can emerge at any age, CTE generally affects women between 30 to 60 $\mathrm{yr}$ of age. Five-percent minoxidil solution is used as a treatment of CTE (Habif 2010; Otberg and Shapiro 2012).

\section{Recent Research on Pathogenesis}

Stress has traditionally been linked to the development of telogen effluvium. In particular, the stress-associated factors substance $\mathrm{P}$ and nerve growth factor (NGF) have been shown to decrease hair growth and promote transition to catagen phase (Peters et al. 2006). The two factors are interrelated, as substance $P$ up-regulates the expression of NGF and its catagen-associated receptor. Moreover, substance $\mathrm{P}$ deprives hair follicles of their immune-privileged status (Peters et al. 2007). Hair follicles have been shown to possess a local stress response system akin to the HPA axis, and influences on hair follicle growth by levels of thyroid hormones T3 and T4 have also been discussed (Ito et al. 2005; van Beek et al. 2008). Further research is required for a comprehensive understanding of telogen effluvium pathogenesis.

\section{Anagen Effluvium \\ Clinical Presentation and Management}

Anagen effluvium is another example of diffuse hair loss. Instead of hair shedding, however, as occurs in telogen effluvium, the abnormal hairs break off in anagen effluvium. Radiation therapy and cancer chemotherapy are widely understood to be the precipitating factors for this condition, although poisons such as arsenic and thallium are known causes as well. Cells with high rates of mitotic division, like the matrix and cortex cells of hair follicles, are most susceptible to damage. Symptoms present more quickly and dramatically than in telogen effluvium. Hair loss becomes apparent within 1 to $4 \mathrm{wk}$ after exposure to the causative agent, and approximately $80 \%-90 \%$ of scalp hairs are affected. Damage to the hair shaft leads to narrowing and fracture without bulbs. Hair growth ordinarily recovers after $\sim 4$ mo following termination of chemotherapy, although irreversible hair loss has been reported in cases of multiagent chemotherapeutic regimens (Habif 2010; Otberg and Shapiro 2012).

Much investigation has been undertaken regarding the management of anagen effluvium caused by chemotherapeutic agents. The most 
promising pharmacologic interventions have been minoxidil and AS101, although their benefits were restricted to improvement of symptoms or disease duration and not applicable to prevention (Wang et al. 2006). Scalp cooling may be effective for some patients and is tolerated well in most cases (Grevelman and Breed 2005). Calcipotriol and topical calcitriol have failed to demonstrate preventative or modulating effects in patients (Hidalgo et al. 1999; Bleiker et al. 2005). Multiple avenues are open for investigation to improve treatment options for alopecia in cancer patients.

\section{Loose Anagen Syndrome \\ Clinical Presentation and Management}

The classic loose anagen syndrome (LAS) patient is a blond girl aged 2 to 5 who experiences diffuse hair loss and whose unruly, relatively short hair requires few haircuts (Price and Gummer 1989). The patient profile can deviate from this standard pattern, as LAS has also been observed in males, although the ratio of females to males among the patient population is 6 to 1 . Adults as well as individuals with dark hair can be affected. Cases can be familial or sporadic in nature. The condition is understood to occur because of premature keratinization of the inner root sheath of the hair follicle, thereby reducing its adhesion with the hair shaft cuticle. The resulting hair is at risk for breakage and pain is absent. The duration of anagen phase is shortened, explaining the reduced hair length. Hair grows sparsely, characterized by dull texture. No treatment is available for LAS, but prognosis is good; most patients' symptoms lessen with age (Habif 2010; Otberg and Shapiro 2012).

\section{Recent Research on Pathogenesis}

LAS occasionally presents within the context of genetic disorders such as Noonan's syndrome, coloboma, and hypohidrotic ectodermal dysplasia (Habif 2010). According to recent research, mutation in SHOC2 (Soc-2 suppressor of clear homolog), a leucine-rich repeat-containing protein, causes Noonan-like syndrome with loose anagen hair. The researchers postu- late that SHOC2 may play a part in regulating the growth of epithelial hair follicle stem cells and their derivatives (Cordeddu et al. 2009). Progress is underway toward uncovering the molecular background behind LAS.

\section{TRAUMATIC HAIR LOSS}

\section{Trichotillomania}

\section{Clinical Presentation and Management}

Trichotillomania describes chronic, impulsive hair pulling that causes alopecia. $0.6 \%$ to $13 \%$ of the population is estimated to be afflicted with this condition. More boys than girls are affected by childhood trichotillomania, which normally resolves spontaneously. Among adults, many more women are affected than men. Patients experience an urge that they gratify by pulling out hair, engaging in this task for up to $3 \mathrm{~h}$ per day. They are unable to resist despite negative impacts to their work and or social lives. Trichotillomania is often comorbid with mood or anxiety disorders, and greater incidence of this condition is reported in patients with psychological illness (Habif 2010; Otberg and Shapiro 2012).

Although the frontoparietal area of the scalp is most frequently affected based on ease of access, other regions of the scalp and face are also susceptible. Affected patches are characterized by sparse, irregularly distributed growths of short, fractured hairs. None of the areas will demonstrate complete lack of hair shafts, a distinction between trichotillomania and AA (Habif 2010; Otberg and Shapiro 2012).

Provided the patient is stable psychologically, the problem can resolve following discussion with a physician. Treatment becomes more involved for persistent or severe cases. Among the various options, behavioral therapy has been determined to yield greater benefit than clomipramine, and the efficacy of selective serotonin reuptake inhibitors may be equivalent to placebo. Support for the patient is important in confronting this difficult condition (Habif 2010).

\section{Recent Research on Pathogenesis}

An interesting development in the field of trichotillomania research is the discovery that 
Hoxb8 mutant mice showed compulsive hairpulling similar to that observed in humans. Mutation in this gene impairs bone-marrowderived microglia in the brain, causing hair removal and intense grooming (Chen et al. 2010). The study represents an important step forward toward comprehension of the molecular workings behind trichotillomania.

\section{Traction Alopecia}

\section{Clinical Presentation and Management}

Traction alopecia results from tension applied persistently to hair, such as in the case of certain hairstyles including tight ponytails and braids, and also from hair styling devices like hot rollers and hair straighteners. Affected areas correspond to areas under the greatest amounts of pressure, and usually hair loss occurs at scalp margins. Traction alopecia is usually transient, although scarring or signs of inflammation may be observed. With early detection and management, reversal of symptoms generally occurs within a few months. Because of the association between specific hairstyles and cultures, certain populations are especially vulnerable to this condition; for instance, braiding and weaving in African-American females increase the prevalence of traction alopecia in this group (Callender et al. 2004; Habif 2010; Otberg and Shapiro 2012).

To prevent permanent alopecia, patients are advised to switch to more relaxed hairstyles as soon as possible to relieve the stress on their hair. Pharmacological treatments include minoxidil, which has been beneficial for some patients, as well as antibiotics and corticosteroids in the event of folliculitis or inflammation, respectively. Surgical intervention remains an option for patients with advanced hair loss (Callender et al. 2004).

\section{CICATRICIAL ALOPECIAS}

\section{Chronic Cutaneous Lupus Erythematosus}

\section{Clinical Presentation and Management}

Chronic cutaneous lupus erythematosus (CCLE) is a progressive disease of the skin that manifests as scaly, erythematous plaques with well-demarcated borders. These may eventually become atrophic, and patients often experience pruritus and tenderness at the scalp. Sun-exposed areas like the scalp, face, and ears are most susceptible. The condition is usually confined to the skin but coincides with systemic lupus erythematosus (SLE) in some patients (Hordinsky 2008). CCLE has various forms, the most common of which is discoid lupus erythematosus (DLE), accounting for approximately $50 \%-85 \%$ of all cases. DLE is most frequently observed in individuals aged 20 to 45 , with more women than men affected. Cases among African-Americans are reportedly more severe than for other races. DLE is distinguished from other cicatricial alopecias in that erythema, scaling, and changes in pigmentation can be dramatic and feature most prominently at the centers of lesions rather than at the edges. The "carpet tack" sign is associated with DLE, describing scales that show follicular spikes on the undersurface. Follicular plugging and dilation of follicular orifices occur as lesions age, but these signs gradually fade as plaques atrophy, leaving smooth scars. DLE can be localized or generalized (Hordinsky 2008; Wolff et al. 2009; Habif 2010).

Routine application of sunscreens with SPF more than 30 is important for prevention of DLE. Topical and intralesional corticosteroids, calcineurin inhibitors, antimalarials, and retinoids are some of the available options for treatment. For DLE with more extensive involvement, the choices include cyclosporine, hydroxychloroquine sulfate, retinoids, and azathioprine (Hordinsky 2008; Habif 2010). A recent retrospective cohort study examined hydroxychloroquine efficacy and verified clinical response to the drug in the majority of patients. Lack of response was correlated with generalized disease and comorbidity with SLE. These results offer factors to consider in predicting response to hydroxychloroquine (Wahie et al. 2011).

\section{Recent Research on Pathogenesis}

DLE pathophysiology still remains poorly understood. T-lymphocyte infiltration has long 
been predicted to contribute to the condition. In particular, autoreactive $\mathrm{CD} 8^{+} \mathrm{T}$ lymphocytes and type I interferons have been linked to scarring in DLE (Hordinsky 2008). More recently, the type III interferon IFN- $\lambda$ and its receptor were discovered to be overexpressed in the epidermis of DLE lesions. Indeed, human keratinocytes exposed to IFN- $\lambda 1$ increased production of proinflammatory cytokines associated with the development of CLE lesions. Thus, type III interferons possibly contribute to DLE pathogenesis (Zahn et al. 2011).

Additionally, the damage-associated molecular pattern molecules myeloid-related protein8 (Mrp8) and Mrp14 have been shown to play a role in this process. Mrp8 and Mrp14 are upregulated in epidermal cells from the lesions of patients with cutaneous lupus erythematosus, and the expression of these genes is involved in the induction of self-reactive cytotoxic $\mathrm{T}$ lymphocytes. Furthermore, Mrp8 and Mrp14 play roles in the toll-like receptor 4 signaling pathway, which stimulates expression of interleukin-17 (Loser et al. 2010). Another study investigated Ro52, an E3 ubiquitin ligase; autoantibodies targeting Ro52 have previously been correlated with cutaneous lupus erythematosus. Levels of Ro52 expressed by epidermal cells from CCLE lesions were elevated, and UV radiation increased Ro52 levels. The investigators suggest that sun exposure stimulates Ro52 expression, triggering the production of Ro52 autoantibodies and the development of skin lesions (Oke et al. 2009). These studies shed interesting insight on the mechanisms of DLE pathogenesis and provide opportunities for the development of novel therapies.

\section{Lichen Planopilaris}

\section{Clinical Presentation and Management}

Lichen planopilaris (LPP), also known as follicular lichen planus of the scalp, is a rare cicatricial alopecia that occurs because of autoimmune attack of hair follicles, mediated by cell-based immunity. LPP is considered a variant form of lichen planus, an inflammatory disorder of skin and mucous membranes caused by keratinocyte-targeting autoreactive $\mathrm{T}$ lymphocytes. The exact cause remains unclear for lichen planus and LPP. However, risk factors have been identified, including viral infections (such as hepatitis $\mathrm{C}$ virus), contact with metals like gold, and use of certain medications such as thiazide diuretics and quinine (Kang et al. 2008; Otberg and Shapiro 2012).

Adult women make up the majority of the LPP patient population. The crown and parietal areas of the scalp are most commonly affected, and multiple focal lesions may gradually fuse to form extensive regions of alopecia. Classic LPP lesions typically have a smooth white appearance with central scarring and absence of follicle openings. The edges show erythema and scaling around hair follicles. In addition to increased hair loss, patients may experience burning, pruritus, and stinging. Aside from classic LPP, the other subtypes of LPP are frontal fibrosing alopecia (FFA) and Graham-Little syndrome. FFA is seen mostly in postmenopausal women, presenting as a band-like pattern of hair loss predominantly at the frontal hairline. Eyebrow involvement is common. Graham-Little syndrome, on the other hand, consists of the following triad: scalp cicatricial alopecia, lichen planus spinulosus (extensive patches of follicular keratotic papules), and noncicatricial alopecia at the pubic and axillary regions (Kang et al. 2008; Habif 2010).

Intralesional corticosteroid injections constitute first-line therapy for LPP that affects $<10 \%$ of the scalp. These can be combined with topical corticosteroids for further symptom relief. In the case of fulminant LPP, oral corticosteroids are prescribed. Hydroxychloroquine therapy is geared toward patients with $>10 \%$ of their scalp affected by LPP or who do not respond to corticosteroids. For patients who do not improve after treatment with corticosteroids or hydroxychloroquine after 3 to 6 mo, immunomodulating agents cyclosporine and mycophenolate mofetil serve as options. Adding topical minoxidil to the regimen will aid in preventing hair loss. Other pharmacological approaches that have been tested and showed some benefit include thalidomide, tetracycline, dapsone, and isotretinoin. Surgical 
alternatives like hair transplants are also available (Cevasco et al. 2007; Kang et al. 2008; Habif 2010).

\section{Recent Research on Pathogenesis}

Significant advances have been made in recent years toward understanding LPP etiology. Researchers have managed to highlight associations between specific genes and LPP. In one study, gene expression patterns of normal scalp and LPP lesions were compared via microarray. Scalp areas affected by LPP were characterized by diminished expression of genes involved in peroxisome production and lipid metabolism. Further bioinformatic analysis identified reduced expression of the transcription factor peroxisome proliferator-activated receptor $\gamma$ (PPAR $\gamma)$. The researchers then generated PPAR $\gamma$ knockout mice in which the gene mutation is targeted to follicular stem cells expressing KRT15. These mice developed cicatricial alopecia with pruritus, resembling the clinical presentation of LPP patients. Thus, PPAR $\gamma$ represents a novel target in LPP therapy (Karnik et al. 2009). The evidence regarding PPAR $\gamma$ is corroborated by findings in defolliculated or Gsdma3 (gasdermin A3) mutant mice. Gsdma3 is a gene involved in regulating epidermal differentiation, and the mutant mice show signs of cicatricial alopecia (Lunny et al. 2005). There is decreased PPAR $\gamma$ expression in Gsdma3 mutant mice such that these mice may be used to investigate therapy innovations (Ruge et al. 2011). PPAR $y$ agonists have been tried for LPP treatment with mixed to moderate results (Karnik et al. 2009; Baibergenova and Walsh 2012).

Furthermore, microarray results demonstrated an increased expression of the aryl hydrocarbon receptor (AhR) in LPP lesions (Karnik et al. 2009). AhR is a xenobiotic receptor (a receptor for foreign chemicals) that has been found to reduce PPAR $\gamma$ expression on exposure to dioxin-like substances (Hanlon et al. 2003; Cimafranca et al. 2004). Dioxins accumulate in animals exposed to environmental contaminants, and through consumption of their meat, humans are exposed to dioxin (Mozaffarian and Rimm 2006). Thus, there may be a role for for- eign toxins, mediated by the AhR pathway, in the pathogenesis of LPP.

\section{Central Centrifugal Cicatricial Alopecia}

\section{Clinical Presentation and Management}

The North American Hair Research Society defines central centrifugal cicatricial alopecia (CCCA) as the scarring hair loss typically occurring at the crown that mostly affects African-American females. Synonyms include hotcomb alopecia, as the condition was originally known, and follicular degeneration syndrome. The classic patient is a middle-aged AfricanAmerican woman, although the condition has been observed in younger women as well as men. Individuals of other races are rarely affected. Hair loss usually begins at the vertex and expands outward symmetrically, eventually affecting the entire scalp. The active phase, during which inflammatory attacks on hair follicles persist, lasts for several years but is generally self-limiting. Lymphocytes predominate in the infiltrates at the edge of balding lesions with signs of inflammation (Whiting and Olsen 2008; Otberg and Shapiro 2012).

The cause of CCCA remains unclear. In accordance with its former name (hot-comb alopecia), the condition was originally believed to present following use of hot combs, the effects of which were exacerbated by chemicals and application of physical pressure. However, given that a majority of African-American women have used hair relaxers, but $<6 \%$ show signs of extensive central hair loss, it is likely that hairstyling methods are not the only cause (Olsen et al. 2011). Autoimmune and genetic components are under consideration as well. Aside from these, infections and association with female pattern hair loss have been named as contributing factors. There remains much opportunity for research in this area (Whiting and Olsen 2008).

To manage CCCA, patients are advised to refrain as much as possible from inflicting damage to their scalp via various hairstyling methods. These include greasing the scalp, using hot combs and relaxers, and wearing taxing styles 
like cornrows and tight braids. Maintaining a natural hairstyle for at least a temporary period may allow for some recovery by the patient's hair and scalp. As for pharmacological approaches, the common objective is to reduce inflammation. Topical corticosteroids and immunomodulators (tacrolimus and pimecrolimus), oral antibiotics like tetracycline, intralesional injections of corticosteroids, and short courses of oral corticosteroids are available options for patients. Topical minoxidil may be given to encourage hair growth, and hairpieces are a nonpharmacological alternative (Whiting and Olsen 2008).

\section{Recent Research on Pathogenesis}

It has been discussed previously in this section that PPAR $\gamma$ dysfunction may contribute to development of LPP. For CCCA, a coactivator of PPAR $\gamma$ is reportedly down-regulated (Price and Mirmirani 2011). Foreign toxins such as dioxins, a class of chemicals mentioned earlier with regard to their suppression of PPAR $\gamma$ via the AhR, may also contribute to the pathogenesis of CCCA, although more investigation is necessary to confirm this claim.

Researchers have additionally examined the role of cytokeratin 75 (K75). Premature desquamation of the inner root sheath (PDIRS) is recognized as a histological marker for CCCA, and K75 is expressed by the hair follicle companion layer, which serves as an interface for the desquamation process. Analyses of normal scalp and CCCA-affected scalp revealed that K75 expression diminishes during the initial stages of inner root sheath desquamation and eventually disappears (Sperling et al. 2010). Although the investigators of the study do not predict a direct role for K75 in CCCA pathogenesis, its association with PDIRS presents prospects for further inquiry.

Yet another path for inquiry in CCCA research concerns the sebaceous gland. Inflammation and loss of sebaceous glands were frequently observed as early findings in primary cicatricial alopecias, including CCCA (Al-Zaid et al. 2011). The inflammatory activity of sebum may therefore be implicated in CCCA patho- physiology, with much opportunity for research in this area.

\section{FUTURE RESEARCH DIRECTIONS}

Various approaches in the realm of alopecia research are continuing to determine the mechanisms behind disease processes. Numerous transgenic mice have already contributed invaluable knowledge to the field, as discussed earlier in this article. To create them is labor intensive with a high risk for failure. When successful, however, the phenotypes in the transgenic mice may have striking overlap to human pathology and provide powerful support for the involvement of the gene in question. These animals can then serve as models for investigation of novel therapies. In the most effective examples of productive research, these biologic models are paired with in vitro assays to better define mechanism. Although these do not demonstrate clinical presentations as elegantly as knockout mice, they allow for far more simplification and control. A third arena for research that often can precede the previous two are for exploring genetic questions on either small-scale expression screens or larger-scale, genome-wide association studies. Overall, it is clear that the domain of alopecia research will benefit from combining these three avenues.

Basic and applied research strategies in hair follicle biology are also describing potential new avenues for treatment of hair loss conditions and methods to induce new hair growth. From careful promotion of Sonic hedgehog signaling (Callahan and Oro 2001; Paladini et al. 2005) to stimulating Wnt signaling (Gat et al. 1998), clear targets exist to manipulate hair follicle cycling and/or growth. Modulating prostaglandins represents another exciting new direction for therapeutics (Wolf et al. 2003). Future research will explore the use of cellular therapy for alopecia (Stenn and Cotsarelis 2005), such as autologous dermal papillae cells to induce a hair follicle. Additionally, induced pluripotent stem cells might be coaxed into hair follicle lineages to promote hair growth (Itoh et al. 2011; Veraitch et al. 2012). Therapies involving RNA silencing are also among the emerging possibil- 
ities for treatment of alopecias (Dugour et al. 2009). Indeed, fundamental shifts in research from describing pathogenesis defects to developing interventions to treat those defects are underway (Uitto et al. 2012). It is an exciting time in the field of hair research-much progress has been made, and there is much opportunity for further advances.

\section{REFERENCES}

Al-Zaid T, Vanderweil S, Zembowicz A, Lyle S. 2011. Sebaceous gland loss and inflammation in scarring alopecia: A potential role in pathogenesis. J Am Acad Dermatol 65: 597-603.

Bahta AW, Farjo N, Farjo B, Philpott MP. 2008. Premature senescence of balding dermal papilla cells in vitro is associated with $\mathrm{pp} 16^{\mathrm{INK} 4 \mathrm{a}}$ expression. J Invest Dermatol 128: $1088-1094$.

Baibergenova A, Walsh S. 2012. Use of pioglitazone in patients with lichen planopilaris. J Cutan Med Surg 16: 97 100.

Betz RC, Pforr J, Flaquer A, Redler S, Hanneken S, Eigelshoven S, Kortüm AK, Tüting T, Lambert J, De Weert J, et al. 2007. Loss-of-function mutations in the filaggrin gene and alopecia areata: Strong risk factor for a severe course of disease in patients comorbid for atopic disease. J Invest Dermatol 127: 2539-2543.

Bleiker TO, Nicolaou N, Traulsen J, Hutchinson PE. 2005. "Atrophic telogen effluvium" from cytotoxic drugs and a randomized controlled trial to investigate the possible protective effect of pretreatment with a topical vitamin D analogue in humans. Br J Dermatol 153: 103-112.

Callahan CA, Oro AE. 2001. Monstrous attempts at adnexogenesis: Regulating hair follicle progenitors through Sonic hedgehog signaling. Curr Opin Genet Dev 11: 541-546.

Callender VD, McMichael AJ, Cohen GF. 2004. Medical and surgical therapies for alopecias in black women. Dermato Ther 17: 164-176.

Cevasco NC, Bergfeld WF, Remzi BK, de Knott HR. 2007. A case-series of 29 patients with lichen planopilaris: The Cleveland Clinic Foundation experience on evaluation, diagnosis, and treatment. J Am Acad Dermatol 57: 47-53.

Chen S-K, Tvrdik P, Peden E, Cho S, Wu S, Spangrude G, Capecchi MR. 2010. Hematopoietic origin of pathological grooming in Hoxb8 mutant mice. Cell 141: $775-785$.

Cimafranca MA, Hanlon PR, Jefcoate CR. 2004. TCDD administration after the pro-adipogenic differentiation stimulus inhibits PPAR $\gamma$ through a MEK-dependent process but less effectively suppresses adipogenesis. Toxicol Appl Pharmacol 196: 156-168.

Cordeddu V, Di Schiavi E, Pennacchio LA, Ma'ayan A, Sarkozy A, Fodale V, Cecchetti S, Cardinale A, Martin J, Schackwitz W, et al. 2009. Mutation of SHOC2 promotes aberrant protein $N$-myristoylation and causes Noonanlike syndrome with loose anagen hair. Nat Genet 41: $1022-1026$
Dugour A, Hagelin K, Smus C, Balañá ME, Kerner N. 2009. Silencing the androgen receptor: New skills for antiandrogen oligonucleotide skin and hair therapy. J Dermatol Sci 54: 123-125.

Garza LA, Yang C-C, Zhao T, Blatt HB, Lee M, He H, Stanton DC, Carrasco L, Spiegel JH, Tobias JW, et al. 2011. Bald scalp in men with androgenetic alopecia retains hair follicle stem cells but lacks CD200-rich and CD34-positive hair follicle progenitor cells. J Clin Invest 121: 613622.

Garza LA, Liu Y, Yang Z, Alagesan B, Lawson JA, Norberg SM, Loy DE, Zhao T, Blatt HB, Stanton DC, et al. 2012. Prostaglandin D2 inhibits hair growth and is elevated in bald scalp of men with androgenetic alopecia. Sci Transl Med 4: 126 ra34.

Gat U, DasGupta R, Degenstein L, Fuchs E. 1998. De Novo hair follicle morphogenesis and hair tumors in mice expressing a truncated $\beta$-catenin in skin. Cell 95: 605-614.

Gilhar A, Etzioni A, Paus R. 2012. Alopecia areata. New Engl J Med 366: 1515-1525.

Grevelman EG, Breed WPM. 2005. Prevention of chemotherapy-induced hair loss by scalp cooling. Ann Oncol 16: $352-358$.

Habif TP. 2010. Hair diseases. In Clinical dermatology, 5th ed. Mosby, Maryland Heights, MO.

Hanlon PR, Ganem LG, Cho YC, Yamamoto M, Jefcoate CR. 2003. AhR- and ERK-dependent pathways function synergistically to mediate 2,3,7,8-tetrachlorodibenzop-dioxin suppression of peroxisome proliferator-activated receptor- $\gamma 1$ expression and subsequent adipocyte differentiation. Toxicol Appl Pharmacol 189: 11-27.

Hidalgo M, Rinaldi D, Medina G, Griffin T, Turner J, Von Hoff DD. 1999. A phase I trial of topical topitriol (calcitriol, 1,25-dihydroxyvitamin D3) to prevent chemotherapy-induced alopecia. Anticancer Drugs 10: 393 395.

Hordinsky M. 2008. Cicatricial alopecia: Discoid lupus erythematosus. Dermatol Ther 21: 45-48.

Ito N, Ito T, Kromminga A, Bettermann A, Takigawa M, Kees F, Straub RH, Paus R. 2005. Human hair follicles display a functional equivalent of the hypothalamic-pituitaryadrenal axis and synthesize cortisol. FASEB J 19: 13321334.

Ito T, Ito N, Saatoff M, Hashizume H, Fukamizu H, Nickoloff BJ, Takigawa M, Paus R. 2008. Maintenance of hair follicle immune privilege is linked to prevention of NK cell attack. J Invest Dermatol 128: 1196-1206.

Itoh M, Kiuru M, Cairo MS, Christiano AM. 2011. Generation of keratinocytes from normal and recessive dystrophic epidermolysis bullosa-induced pluripotent stem cells. Proc Natl Acad Sci 108: 8797-8802.

Kang H, Alzolibani AA, Otberg N, Shapiro J. 2008. Lichen planopilaris. Dermatol Ther 21: 249-256.

Karnik P, Tekeste Z, McCormick TS, Gilliam AC, Price VH, Cooper KD, Mirmirani P. 2009. Hair follicle stem cellspecific PPAR $\gamma$ deletion causes scarring alopecia. J Invest Dermatol 129: 1243-1257.

Kwack MH, Sung YK, Chung EJ, Im SU, Ahn JS, Kim MK, Kim JC. 2008. Dihydrotestosterone-inducible dickkopf 1 from balding dermal papilla cells causes apoptosis 
in follicular keratinocytes. J Invest Dermatol 128: 262269.

Loser K, Vogl T, Voskort M, Lueken A, Kupas V, Nacken W, Klenner L, Kuhn A, Foel D, Sorokin L, et al. 2010. The Toll-like receptor 4 ligands Mrp8 and Mrp14 are crucial in the development of autoreactive $\mathrm{CD}^{+} \mathrm{T}$ cells. Nat Med 16: 713-717.

Lunny DP, Weed E, Nolan PM, Marquardt A, Augustin M, Porter RM. 2005. Mutations in gasdermin 3 cause aberrant differentiation of the hair follicle and sebaceous gland. J Invest Dermatol 124: 615-621.

Messenger AG, Rundegren J. 2004. Minoxidil: Mechanisms of action on hair growth. Br J Dermatol 150: 186-194.

Mikkola ML, Thesleff I. 2003. Ectodysplasin signaling in development. Cytokine Growth Factor Rev 14: 211-224.

Mozaffarian D, Rimm EB. 2006. Fish intake, contaminants, and human health: Evaluating the risks and the benefits. JAMA 296: 1885-1899.

Norwood OT. 1975. Male pattern baldness: Classification and incidence. South Med J 68: 1359-1365.

Norwood OT. 2001. Incidence of female androgenetic alopecia (female pattern alopecia). Dermatol Surg 27: 53-54.

Oke V, Vassilaki I, Espinosa A, Strandberg L, Kuchroo VK, Nyberg F, Wahren-Herlenius M. 2009. High Ro52 expression in spontaneous and UV-induced cutaneous inflammation. J Invest Dermatol 129: 2000-2010.

Olsen EA, Callender V, McMichael A, Sperling L, Anstrom KJ, Shapiro J, Roberts J, Durden F, Whiting D, Bergfeld W. 2011. Central hair loss in African American women: Incidence and potential risk factors. J Am Acad Dermatol 64: $245-252$.

Otberg N, Shapiro J. 2012. Hair growth disorders. In Fitzpatrick's dermatology in general medicine, 8th ed. (ed. Goldsmith LA, et al.). McGraw-Hill, New York.

Paladini RD, Saleh J, Qian C, Xu G-X, Rubin LL. 2005 Modulation of hair growth with small molecule agonists of the hedgehog signaling pathway. J Invest Dermatol 125: $638-646$.

Paus R, Cotsarelis G. 1999. The biology of hair follicles. $N$ Engl J Med 341: 491-497.

Peters EMJ, Arck PC, Paus R. 2006. Hair growth inhibition by psychoemotional stress: A mouse model for neural mechanisms in hair growth control. Exp Dermatol 15: $1-13$.

Peters EMJ, Liotiri S, Bodó E, Hagen E, Bíró T, Arck PC, Paus R. 2007. Probing the effects of stress mediators on the human hair follicle: Substance P holds central position. Am J Pathol 171: 1872-1886.

Petukhova L, Duvic M, Hordinsky M, Norris D, Price V, Shimomura Y, Kim H, Singh P, Lee A, Chen WV, et al. 2010. Genome-wide association study in alopecia areata implicates both innate and adaptive immunity. Nature 466: 113-117.

Price VH, Gummer CL. 1989. Loose anagen syndrome. J Am Acad Dermatol 20: 249-256.

Price V, Mirmirani P. 2011. Mechanisms and current research. In Cicatricial alopecia (ed. Price V, Mirmirani P), pp. 31-34. Springer, New York.

Price VH, Hordinsky MK, Olsen EA, Roberts JL, Siegfried EC, Rafal ES, Korman NJ, Altrabulsi B, Lueng HM, Gar- ovoy MR, et al. 2008. Subcutaneous efalizumab is not effective in the treatment of alopecia areata. J Am Acad Dermatol 58: 395-402.

Prodi DA, Pirastu N, Maninchedda G, Sassu A, Picciau A, Palmas MA, Mossa A, Persico I, Adamo M, Angius A, et al. 2008. EDA2R is associated with androgenetic alopecia. J Invest Dermatol 128: 2268-2270.

Ruge F, Glavini A, Gallimore AM, Richards HE, Thomas CP, O’Donnell VB, Philpott MP, Porter RM. 2011. Delineating immune-mediated mechanisms underlying hair follicle destruction in the mouse mutant defolliculated. J Invest Dermatol 131: 572-579.

Siebenhaar F, Sharov AA, Peters EMJ, Sharova TY, Syska W, Mardaryev AN, Freyschmidt-Paul P, Sundberg JP, Maurer M, Botchkarev VA. 2007. Substance P as an immunomodulatory neuropeptide in a mouse model for autoimmune hair loss (alopecia areata). J Invest Dermatol 127: 14891497.

Sperling LC, Hussey S, Sorrells T, Wang J, Darling T. 2010. Cytokeratin 75 expression in central, centrifugal, cicatricial alopecia-New observations in normal and diseased hair follicles. J Cutan Pathol 37: 243-248.

Stenn KS, Cotsarelis G. 2005. Bioengineering the hair follicle: Fringe benefits of stem cell technology. Curr Opin Biotechnol 16: 493-497.

Strober BE, Siu K, Alexis AF, Kim G, Washenik K, Sinha A, Shupack JL. 2005. Etanercept does not effectively treat moderate to severe alopecia areata: An open-label study. J Am Acad Dermatol 52: 1082-1084.

Strober BE, Menon K, McMichael A, Hordinsky M, Krueger G, Panko J, Siu K, Lustgarten JL, Ross EK, Shapiro J. 2009. Alefacept for severe alopecia areata: Randomized, double-blind, placebo-controlled study. Arch Dermatol 145: 1262-1266.

Uitto J, Christiano AM, McLean WHI, McGrath JA. 2012. Novel molecular therapies for heritable skin disorders. J Invest Dermatol 132: 820-828.

van Beek N, Bodó E, Kromminga A, Gáspár E, Meyer K, Zmijewski MA, Slominski A, Wenzel BE, Paus R. 2008. Thyroid hormones directly alter human hair follicle functions: Anagen prolongation and stimulation of both hair matrix keratinocyte proliferation and hair pigmentation. J Clin Endocrinol Metab 93: 4381-4388.

Veraitch OK, Kobayashi T, Imaizumi Y, Akamatsu W, Amagai M, Okano H, Ohyama M. 2012. Human induced pluripotent stem cell-derived keratinocyte precursors contribute to hair follicle regeneration in vivo. In Society for Investigative Dermatology Annual Meeting. Raleigh, NC.

Wahie S, Daly AK, Cordell HJ, Goodfield MJ, Jones SK, Lovell CR, Carmichael AJ, Carr MM, Drummond A, Natarajan S, et al. 2011. Clinical and pharmacogenetic influences on response to hydroxychloroquine in discoid lupus erythematosus: A retrospective cohort study. J Invest Dermatol 131: 1981-1986.

Wang J, Lu Z, Au JL-S. 2006. Protection against chemotherapy-induced alopecia. Pharma Res 23: 2505-2514.

Watt FM., Collins CA. 2008. Role of $\beta$-catenin in epidermal stem cell expansion, lineage selection, and cancer. Cold Spring Harb Symp Quant Biol 73: 503-512. 
J. Qi and L.A. Garza

Whiting DA, Olsen EA. 2008. Central centrifugal cicatricial alopecia. Dermatol Ther 21: 268-278.

Wolf R, Matz H, Zalish M, Pollack A, Orion E. 2003. Prostaglandin analogs for hair growth: Great expectations. Dermatol Online J 9: 7.

Wolff K, Johnson RA, Suurmond D. 2009. Disorders of hair follicles and related disorders. In Fitzpatrick's color atlas and synopsis of clinical dermatology, 6th ed. (ed. Wolff K, et al.). McGraw-Hill, New York.

Zahn S, Rehkämper C, Kümmerer BM, Ferring-Schmidt S, Bieber T, Tüting T, Wenzel J. 2011. Evidence for a pathophysiological role of keratinocyte-derived type III inter- feron (IFN $\lambda$ ) in cutaneous lupus erythematosus. J Invest Dermatol 131: 133-140.

Zhang X, Yu M, Yu W, Weinberg J, Shapiro J, McElwee KJ. 2009. Development of alopecia areata is associated with higher central and peripheral hypothalamic-pituitary-adrenal tone in the skin graft induced $\mathrm{C} 3 \mathrm{H} / \mathrm{HeJ}$ mouse model. J Invest Dermatol 129: 1527 1538.

Zhuo FL, Xu W, Wang L, Wu Y, Xu ZL, Zhao JY. 2012. Androgen receptor gene polymorphisms and risk for androgenetic alopecia: A meta-analysis. Clin Exp Dermatol 37: $104-111$. 


\section{$\&_{\mathrm{CSH}}^{\infty} \&$ Cold Spring Harbor

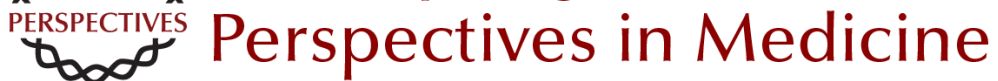

\section{An Overview of Alopecias}

Ji Qi and Luis A. Garza

Cold Spring Harb Perspect Med 2014; doi: 10.1101/cshperspect.a013615

Subject Collection The Skin and Its Diseases

Melanoma: Clinical Features and Genomic Insights

Elena B. Hawryluk and Hensin Tsao

Wound Healing and Skin Regeneration

Makoto Takeo, Wendy Lee and Mayumi Ito

The Dermal Papilla: An Instructive Niche for

Epithelial Stem and Progenitor Cells in

Development and Regeneration of the Hair Follicle Bruce A. Morgan

Immunology and Skin in Health and Disease Jillian M. Richmond and John E. Harris

Desmosomes: Regulators of Cellular Signaling and Adhesion in Epidermal Health and Disease Jodi L. Johnson, Nicole A. Najor and Kathleen J. Green

Markers of Epidermal Stem Cell Subpopulations in Adult Mammalian Skin Kai Kretzschmar and Fiona M. Watt

Psoriasis

Paola Di Meglio, Federica Villanova and Frank O. Nestle

Cell Therapy in Dermatology Gabriela Petrof, Alya Abdul-Wahab and John A. McGrath
Modeling Cutaneous Squamous Carcinoma

Development in the Mouse

Phillips Y. Huang and Allan Balmain

Natural and Sun-Induced Aging of Human Skin Laure Rittié and Gary J. Fisher

Advanced Treatment for Basal Cell Carcinomas Scott X. Atwood, Ramon J. Whitson and Anthony E. Oro

Epidermal Polarity Genes in Health and Disease Frederik Tellkamp, Susanne Vorhagen and Carien M. Niessen

Induced Pluripotent Stem Cells in Dermatology:

Potentials, Advances, and Limitations Ganna Bilousova and Dennis R. Roop

The Genetics of Human Skin Disease Gina M. DeStefano and Angela M. Christiano

p53/p63/p73 in the Epidermis in Health and Disease

Vladimir A. Botchkarev and Elsa R. Flores

Diversification and Specialization of Touch

Receptors in Skin

David M. Owens and Ellen A. Lumpkin

For additional articles in this collection, see http://perspectivesinmedicine.cshlp.org/cgi/collection/ 